\title{
Barriers to cervical cancer screening in Mulanje, Malawi: a qualitative study
}

\author{
This article was published in the following Dove Press journal: \\ Patient Preference and Adherence \\ II March 201 I \\ Number of times this article has been viewed
}

\section{Victoria K Fort ${ }^{1}$ \\ Mary Sue Makin ${ }^{2}$ \\ Aaron J Siegler' \\ Kevin Ault ${ }^{3}$ \\ Roger Rochat ${ }^{1}$}

'Rollins School of Public Health, Atlanta, Georgia, USA; ${ }^{2}$ Mulanje Mission Hospital, Mulanje, Malawi; ${ }^{3}$ Emory University Medical School, Atlanta, Georgia, USA
Correspondence: Victoria Fort I39 Walthall St. SE, Atlanta, GA 30316, USA

$\mathrm{Tel}+\mid$ 93|-636-6300

Email victoria.fort@gmail.com
Background: In Malawi, cervical cancer is the most prevalent form of cancer among women, with an $80 \%$ mortality rate. The Mulanje Mission Hospital has offered free cervical cancer screening for eight years; however, patients primarily seek medical help for gynecologic complaints after the disease is inoperable.

Methods: We investigated how women in rural Malawi make health-seeking decisions regarding cervical cancer screening using qualitative research methods. The study was conducted between May and August of 2009 in Mulanje, Malawi.

Results: This study found that the primary cue to action for cervical cancer screening was symptoms of cervical cancer. Major barriers to seeking preventative screening included low knowledge levels, low perceived susceptibility and low perceived benefits from the service. Study participants did not view cervical cancer screening as critical health care. Interviews suggested that use of the service could increase if women are recruited while visiting the hospital for a different service.

Conclusion: This study recommends that health care providers and health educators target aspects of perceived susceptibility among their patients, including knowledge levels and personal risk assessment. We believe that continued support and advertisement of cervical cancer screening programs along with innovative recruitment strategies will increase usage density and decrease unnecessary deaths from cervical cancer in Malawi.

Keywords: cervical cancer, interviews, health care, Mulanje Mission Hospital

\section{Introduction and background}

The story of Gertrude Ngoma (names have been changed)

In the early morning hours of July 4th, 2009, Gertrude Ngoma was brought by ambulance to the Mulanje Mission Hospital. At 34 years of age with six children, she was dying from untreated cervical cancer as it overwhelmed her body. She had only days to live and was being transferred to hospice care.

Cervical cancer affects an estimated 530,000 women worldwide each year, more than half of whom die from the disease. ${ }^{1}$ The majority of the burden $(80 \%-90 \%)$ affects women who live in developing countries. ${ }^{1}$ In Malawi, cervical cancer is the most prevalent form of cancer among women, with a mortality rate of $80 \%{ }^{2}$ Cervical cancer prevention and treatment programs can be tailored to local health system needs and are well documented in the reduction of cervical cancer mortality. ${ }^{3}$

In the late 1980s, Malawi attempted a nation-wide cytology-based cervical cancer screening program, though this program quickly deteriorated for lack of resources, trained professionals and absence of infrastructure. ${ }^{4}$ Limited resources remain 
a serious impediment to health care delivery in the country. ${ }^{5}$ The World Health Organization's recommendation for low-resource countries is visual inspection with acetic acid (VIA) as an effective method of reducing the burden of cervical cancer. ${ }^{6}$ VIA is the current method of cervical cancer screening in Malawi. VIA provides a single-visit approach in which providers visualize the cervix using household vinegar to detect precancerous cells on the cervix in lowresource settings. ${ }^{7,8}$

The Mulanje Mission Hospital (MMH) in Mulanje, Malawi, started offering VIA as a free service in 2001 through the help of Project Hope and JHPIEGO, the research and program arm of Johns Hopkins University. Statistical data for local utilization of screening is unpublished but observations by gynecologist and co-author Dr. Makin suggest that many women in the Mulanje District never come for screening, and invasive, incurable cancer is still common. Previous studies on barriers to cervical cancer screening identified knowledge about cervical cancer screening, ${ }^{9,10}$ education level,,${ }^{11,12}$ family history of the disease,${ }^{13}$ and costs, ${ }^{14}$ as the most significant barriers to getting screened. This study aims to get a better understanding of the complex barriers that prevent women in Mulanje, Malawi from getting early cervical cancer screening.

\section{Methods}

Between May and August of 2009, our research team facilitated twenty in-depth interviews in Mulanje, Malawi. We used a semi-structured interview guide to collect information regarding attitudes and behaviors related to cervical cancer screening and general utilization of health services. The research team consisted of three interviewers, one transcriptionist and five translators to conduct and transcribe the interviews in the local language, Chichewa. The team identified two sites for recruiting participants, 1) the outpatient department of the Mulanje Mission Hospital where women had come to utilize the free cervical cancer screening service and 2) the catchment area of the MMH. Women using the clinic were selected using nonprobability sampling, choosing every third woman to come in for screening. The village interviews were conducted over five villages surrounding the MMH by choosing a landmark in each and approaching every second home until we located one woman in the household who fit our criteria. Inclusion criteria for both groups were that the participant be female and between the ages of 20 and 50. The interview guide was constructed for women using the cervical cancer screening service in order to elucidate the key motivational factors that brought them into the hospital. We piloted the guide first to establish comprehension. The guide was then altered and piloted again for interviews in the villages by taking out questions specific to getting screened and including more questions about general health-seeking behaviors and knowledge about cervical cancer. Saturation of themes, both inductive and deductive was established after ten interviews from both sites resulting in 20 interviews total. The interviews, averaging 45 minutes, were conducted in Chichewa, and then transcribed verbatim and translated into English. Transcripts were analyzed using the qualitative data software MAXQDA (Marburg, Germany).

The research received approval from the Emory University IRB and the National Health Sciences Research Committee of the Malawi Ministry of Health.

\section{Results}

\section{Conceptual framework: explanation}

The major findings of this research are visually demonstrated in the conceptual framework (Figure 1). This framework is based on the Health Belief Model (HBM) created to explain low levels of cancer screening in the 1950s United States. ${ }^{15}$ This study found that the HBM serves as a useful framework for understanding participant perceptions and behaviours.

\section{Individual perceptions}

\section{Faith in a curative medical system decreases perceived susceptibility}

To someone unfamiliar with the germ theory of disease, hospitals can appear to perform miracles when they rid a body of worms or cure a bout of malaria. Although chronic diseases like cervical cancer do not have a cure, this study found that the women interviewed maintained a high level of faith in medicine. Participants used words like "trust" and "faith" to explain that they believed their doctor would discover what was happening inside of their body. The idea of being diagnosed with cervical cancer was addressed with resignation. Lomi said,

"I cannot get worried. What I can do is to follow the advice

of the hospital and the doctor. If I am found to have the cancer, I will do what they tell me to do to be well”.

This mindset was echoed in other interviews as well. The general sense was that women felt as though their health was the responsibility of the health care provider, and that "he" 


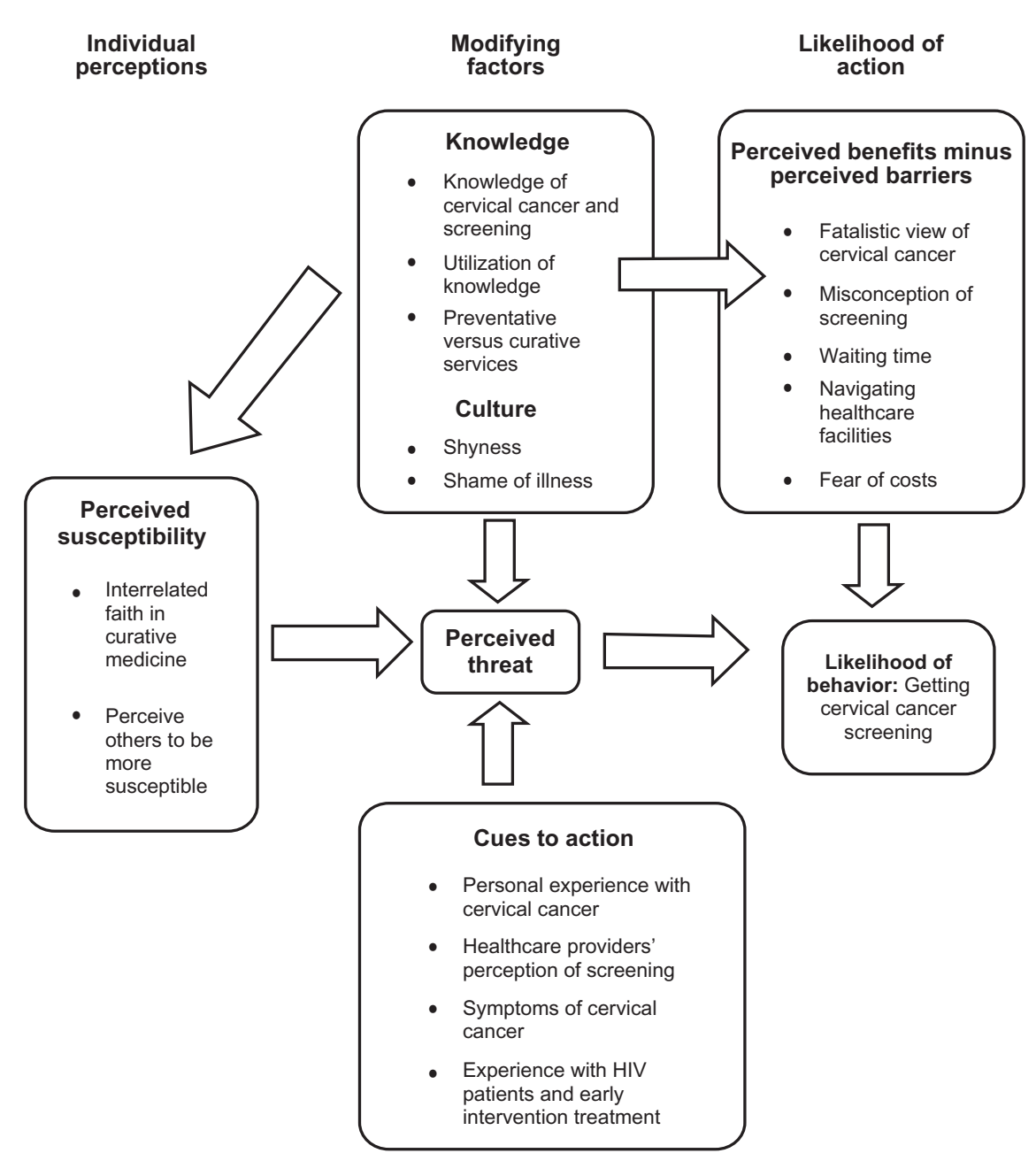

Figurel Participant interviews analysed with the health belief model.

would cure them of any illness. A woman from a nearby village told us that,

"If I happen to go for the test and I am found [reactive],

I feel I will still be happy because doctors will help me to resolve my problem. So if I have cervical cancer, it can be the doctor's responsibility to help me".

Faith in the medical system put the issue of individual risk for disease out of personal control and diffused the fear of having the illness.

\section{Modifying factors}

\section{Low knowledge about cervical cancer and screening}

Knowledge of cervical cancer was very low; the majority of women from the $\mathrm{MMH}$ and the villages could not tell us anything about cervical cancer beyond it being a fatal disease. When asked about cervical cancer screening, women often had no concept of what the screening was for, what happened to a woman while she was being screened, or why it was important to be screened. When asked about the screening process, Blessing, a 30 year-old widow with two children, told her interviewer that she did not know anything about cervical cancer screening, adding,

"I just hear that sometimes they pull out the uterus and they look at it".

Blessing had not been screened, and typical of women interviewed outside of the hospital, was afraid of the service.

\section{Knowledge about cervical cancer used when symptomatic}

For women interviewed who were waiting to be screened, we assessed how they learned about screening and what factors led the women to seek screening services. All of the women had heard about cervical cancer screening 
while at the hospital for another service. Lomi heard about cervical cancer screening while at the District Hospital during a Health Talk in the Outpatient Department, but thought it was useless until she had constant pain. She now has chronic abdominal pain and came for screening to rule out cancer as the cause of her pain. She had not been told to use the screening service before she became ill, only that it could be used in a similar way as HIV and malaria testing.

\section{Cultural factors increase perceived threat} Shame of being "sick" decreases perceived threat of cervical cancer screening

Personal health information was mentioned in a few interviews as being extremely private. For women with a disclosed illness, there was a sense of discomfort and shame associated with the idea that other people knew about their health status. One participant was ashamed that her coworkers knew she was seeking medical care. She worked in a primary school and had taken a few days off over the last few months to go to the hospital for abnormal vaginal bleeding. She told us that she was able to write letters to her supervisor in order to be absent from school, but that he had posted one of her letters in a public place. She said,

"During my second time, I found my letter, my sick report letter, the head teacher had posted it on the notice board [she pointed to the notice board on the wall of the conference room] ... So, ah. It was not private. And I tried to talk to him that that should not be done. And he removed it away ... I felt very exposed to the other teachers, so they were knowing my health status, and I felt shame to have them all know how I was going to the hospital. Now is my third time to be away from work, and they are all aware of that".

Frequently, these in-depth interviews elicited the notion that stigma did not exist in these communities. This participant may not vocalize that this moment was stigmatizing, but she certainly did not want her health-seeking behavior made public.

\section{Likelihood of action}

Fatalistic view of cervical cancer increases perceived barriers

A typical interview with a village participant illuminated the idea of cancer as seen by people living around the MMH. This participant had not been screened, but she had learned about screening from nurses at the Mulanje District Hospital,

"I can say that people believe that cancer is chronic and incurable, so I think that is the reason why women are not willing to go for the test. Because it will mean the same, whether testing or not, and they can become depressed".

She explained the screening process to us as though it were a diagnostic test, and could only detect a deadly illness. This participant had a fatalistic view of cervical cancer and could not see the benefit of screening because she did not think that it could prevent the disease.

Another participant from a village told us,

"Most women feel that if they go for the test, they lose peace of mind and psychologically they will be upset and consequently they will die. Even my sister had the same view".

Most village interviews echoed this fear of being diagnosed with cervical cancer as a major barrier to not being screened themselves. Women interviewed in the hospital thought that fear of being diagnosed and dying soon thereafter was a likely reason that other women were not being screened for cervical cancer.

\section{Time increases perceived barriers}

When asked why she had not been screened, Priscilla replied,

"Ahh. I am more than willing to go in for screening, but I am failing because of a lack for time. I am too busy working in the fields and in my house to go to the hospital for that service".

A village participant was especially frustrated with the waiting times at the District Hospital, citing the double burden of having a child with her. The research team observed children of varying ages with almost every woman of childbearing age, suggesting that this experience was not unique:

"If you go with a child, he or she will cry with hunger until he is tired. One minute they are open the other minute they are closed. This goes on until the afternoon and sometimes we get medicine late in the evening and yet we have come from very far away".

This participant expressed frustration that she was forced to wait on dispensation when she had travelled a long distance and had a hungry, tired child with her. 
Health care facility navigation increases

perceived barriers

Difficulty in navigating health care facilities can increase the perceived barriers women face in getting screened for cervical cancer. Priscilla was afraid of wasting valuable time by waiting in the wrong place for cervical cancer screening, saying,

“I don't know where you must wait. I haven't talked to anyone about what I must do, and I am confused. I am afraid that I will be waiting in the wrong place and not be seen and have to come home".

This participant feared the misuse of time spent sitting and waiting in the wrong place at the hospital, suggesting that the hospital is difficult to navigate. Although this was only brought up in one interview, it is a potential avenue for further study.

\section{Fear of hidden costs increases perceived barriers}

The womens' attitudes towards health facilities in Mulanje revolved around the cost and quality of health services, perceiving a higher level of care at the Mulanje Mission Hospital (MMH) while feeling that the Mulanje District Hospital (MDH) was their only alternative if they could not pay for the better MMH services. One woman told us that she always goes to the MMH.

"There are always problems at the District hospital because the services are free".

Women who had come to get screened told us that many women may be confused about the cost of cervical cancer screening. They knew that the service was free, but they told us that many people see the hospital as a place where you have to pay fees to see the doctor, fees for tests and fees for medicine before you can get your health passport returned. They expressed a genuine fear of being unable to pay for health services, and that this fear may be keeping women from coming to the hospital for a service that is advertised as free because it may have hidden or unexpected costs.

\section{Cues to action}

Personal experience with cervical cancer does not increase perceived threat

Most participants did not believe that they were at risk for cervical cancer. Dorothy, 64 years old with four children, told her interviewer that she had not been screened for cervical cancer, saying,
"Why should I go? Is it worth the test? This disease is not dangerous".

Dorothy went on to explain that a member of her family had been diagnosed with invasive cancer. Her relative had a full hysterectomy, the direct and indirect costs of which she explained in detail. Her perception of personal risk was not influenced by her relative's experience with having cervical cancer.

\section{Chronic abdominal pain as a cue to action}

Women consistently understood cervical cancer screening to be a diagnostic tool instead of a preventative measure. The women at the hospital complained of chronic pain, using the term, "pafupi-fupi" (Chichewa: "constant" or "unremitting") to describe their condition. All but one hospital participant sought cervical cancer screening based on experiencing either abdominal pain or vaginal pathology.

\section{Case study of an outlier: experience with HIV and early intervention as a cue to action}

One woman interviewed before cervical cancer screening came because she had learned about the service while at church and understood that being screened early for the disease could decrease her risk of getting cervical cancer. Grace has two children with HIV and learned from their experience that being diagnosed early in the stages of disease can increase the chances of survival. By demographic characteristics she was similar to the other participants, her main difference being a higher perceived susceptibility to cervical cancer.

Grace overcame the barriers commonly mentioned by village participants. Grace and other hospital users expressed an equivalent ability to get help financially from neighbors and family, but Grace was unique in her willingness to access these sources for the explicit purpose of getting screened for cervical cancer.

Grace knew that being diagnosed late in the development of cancer meant that there was no way to cure the disease. She had personal experience with friends and other women in her village having constant menstruation and being diagnosed with cervical cancer. Grace projected that other people are beginning to realize that a delay in screening can lead to death.

Grace also expressed a more realistic level of trust in the hospital and in the staff being capable of helping people than the other women interviewed. She told us that doctors cannot cure women who had already become sick. 
In closing, Grace made a final statement that sums up her cue to action,

"The people who used to laugh at those who went for VCT, now they are finding out that they happen to be infected.

They cannot be helped. Now they just wish they had gone for VCT earlier, they could also be fine".

\section{Discussion}

This study found that the most prominent barriers women face in seeking cervical cancer screening at the Mulanje Mission Hospital are low knowledge of cervical cancer and a low perceived threat of the disease. Participants were sociodemographically similar across the two sample sites, all of whom live in rural, southern Africa between the ages of 20 and 50, the majority of whom work as subsistence farmers. Comparison analysis across the two samples found that the only difference of care seeking was that women who had immediate symptoms of cervical cancer sought screening. The women were also concerned with the indirect costs of getting screened, including transportation and time. Stigma still exists around being ill, perhaps as an artefact of HIVrelated stigma, creating a barrier to open communication about seeking healthcare.

The role of women as caregivers in Malawian society appears to affect their ability to access healthcare for themselves. The participant that utilized cervical cancer screening correctly was doing so in part based on her experience with two children with HIV and her belief that early screening/testing can save lives. This finding points to previously understood patterns of low preventative service utilization.

The study suggests that women are not likely to utilize a single, preventative service located at a health facility, but may be interested in a service once they have sought care for a more urgent issue. We believe that these findings can be generalized to women of similar backgrounds and demographics.

\section{Recommendations for public health action}

The VIA programs that are already in place in 42 clinics and hospitals require continuous governmental and outside assistance in order to provide high quality services. We recommend that support of these services take into consideration gender-specific roles in Malawian society that may act as barriers to women reaching the screening sites. Cervical cancer screening utilization could potentially be increased by developing comprehensive health education programs focused on susceptibility and risk. The authors also recommend integrating recruitment into programs with high attendance, such as antenatal care, under-five and HIV/AIDS clinics. Reaching women early is the only way to address the growing burden of cervical cancer worldwide.

We believe that the way forward from this study includes a continuation of support and advertisement of current cervical cancer screening programs. We also recommend that surveillance systems continue to monitor and release information regarding the utilization and clinical results of cervical cancer screening services for Malawi in order to more effectively target low-utilization areas and improve service delivery.

\section{Study limitations}

As a qualitative research study, the selection of participants utilized convenience sampling and had a small number of participants.

\section{Acknowledgments}

The authors would like to acknowledge the work of the Mulanje Mission Hospital and its supporting role in the completion of this work. Funding was provided by the OC Hubert Charitable Trust.

\section{Disclosure}

No conflicts of interest were declared in relation to this paper.

\section{References}

1. International Agency for Research on Cancer. Cervical Cancer Incidence and Mortality Worldwide in 2008. Available from: http://globocan.iarc. fr/factsheets/cancers/cervix.asp. 2008. Accessed February 3, 2011.

2. World Health Organization. Cervical Cancer Screening in Developing Countries. Geneva. Available from http://whqlibdoc.who.int/ publications/2002/9241545720. World Health Organization. 2000. Accessed February 3, 2011.

3. Sankaranarayanan, Nene BM, Shastri S, et al. HPV Screening for Cervical Cancer in Rural India. N Engl J Med. 2009;360(14):1385-1395.

4. Kleine A. Malawi Cervical Cancer Prevention Program Needs Assessment: Final Report. JHPIEGO. 2004.

5. Family Health International. Malawi. Available from: http://www.fhi. org/NR/rdonlyres/eeujq7elxm2bb45lkiwvnrstpjuzdvfkcmybkgza33uqax ta6lilbjppefvvlibsb332t3ice3xxpn/malawistireport1.pdf. 2002. Accessed February 3, 2011.

6. World Health Organization. Human Papillomavirus and Related Cancers. Barcelona, Spain: HPV Information Centre; 2009.

7. Alliance for Cervical Cancer Prevention. New evidence on the impact of cervical cancer screening and treatment using HPV DNA tests, visual inspection, or cytology. Available from: http://www.rho.org/files/ ACCP_screening_factsheet_July09.pdf. 2009. Accessed February 3, 2011.

8. Lu RKS. Effective Low-Tech Screening of Cervical Cancer. Available from: http://www.globalhealthmagazine.com/guest_blog/effective_lowtech_screening_of_cervical_cancer/. Accessed February 3, 2011. 
9. Abotchie PN, Shokar NK. Cervical cancer screening among college students in Ghana: knowledge and health beliefs. Int J Gynecol Cancer. 2009;19(3):412-416.

10. Mosavel M, Simon C, Oakar C, Meyer S. Cervical cancer attitudes and beliefs - a Cape Town community responds on World Cervical Cancer Day. J Cancer Educ. 2009;24(2):114-119.

11. Othman ND. Cervical Cancer Screening: Patients' Understanding in Major Hospitals in Malaysia. 2009;10:569-574

12. Uysal AB. Knowledge about cervical cancer risk factors and pap testing behaviors among Turkish women. Asian Pac J Cancer Prev. 2009;10:345-351.
13. Saifari MM. Knowledge, attitudes, and practice related to cervical cancer screening among Kuwaiti women. Med Princ Pract. 2009;18(1): 35-42.

14. Lyttle N, Stadelman K. Assessing awareness and knowledge of breast and cervical cancer among appalachian women. Prev Chronic Dis. 2006;3(4):A125.

15. Champion VS. The Health Belief Model. In: Glanz K, Rimmer BK, editors. Health Behavior and Health Education. San Francisco, CA: Jossey-Bass; 2002:45-66.

Patient Preference and Adherence

\section{Publish your work in this journal}

Patient Preference and Adherence is an international, peer-reviewed, open access journal focusing on the growing importance of patient preference and adherence throughout the therapeutic continuum. Patient satisfaction, acceptability, quality of life, compliance, persistence and their role in developing new therapeutic modalities and compounds to optimize clinical outcomes for existing disease states are major areas of interest. This journal has been accepted for indexing on PubMed Central. The manuscript management system is completely online and includes a very quick and fair peer-review system. Visit http://www.dovepress.com/ testimonials.php to read real quotes from published authors.

Submit your manuscript here: http://www.dovepress.com/patient-preference-and-adherence-journal 